\title{
Teaching Design Engineering: High Innovation or High Adaptation?
}

\author{
Peter H. Gregson, Ph.D., F.E.C., P.Eng. \\ Professor, E\&CE, Dalhousie University \\ peter.gregson@dal.ca
}

\begin{abstract}
Teaching engineering design is fraught with problems, not the least of which is that traditionally, the subject is difficult for both student and professor. We don't think that it needs to be. We attempt to identify and understand the major problem, that of the very considerable difference in the ability to form abstractions, of the professor and the students. Research shows that this ability is essential to gaining experthood, but that the difference in the abilities of teachers and students to form abstractions hinders teaching. We propose a new project-based teaching paradigm, the "Program Projects" and a new teaching environment to help to address the issue.
\end{abstract}

\section{Introduction}

Teaching engineering design is hard, possibly harder than learning it [3]. Need it be so? What are the problems? We believe that many of the problems stem from the basic difference between a novice and an expert; specifially that the expert is one because (s)he can acquire and abstract new situational data in a manner that can be transferred to other problem domains. This is completely unlike the student who has not had the experience to build up the knowledge nets in which and around which these abstractions are formed. Thus, the student does not have the context with which to form abstractions or even to gauge the importance of the new data, and so they are severely hindered in transferring it to other domians.

It has been said that this can only be solved with experience. While that may well be a sufficient condition for its solution, is it a necessary one? We believe that the answre is "no."

We make the case for a new teaching paradigm and environment. The paradigm is an extension of "project-based learning" [3] to a multi-year, multi-course project environment in which student in years two, three and four work together on a major project that incorporates material from multiple courses in each of the years. The environment is a new classroom in which students are required to test and evaluate the material that they learn in lectures, during those lectures. It is a ixture of lab and class.

\section{Background}

To give a context to the following, we must define "high innovation" and "high adaptation."

A "high adaptation" design project is one in which the designer has considerable experience through the conduct of other projects with similar major parts. The designer can take design modules M1 through M10 from Projects A through $\mathrm{C}$, modify them appropriately, and combine them to form Project D. (S)he may 
have to develop module M11 from scratch because (s)he doesn't have previous experience with that combination of functions. Or it may be that the specific configuration of modules M1 through M10 in Project D is unique, and so this is where the innovation happens. However, the bulk of the work is closely based on previous work and so the designer has both experience with the concepts and confidence that (s)he can complete it successfully.

A "high innovation" project is one in which the designer has very little direct previous experience. (S)he doesn't know how to accomplish the design and so (s)he has to conduct considerable research to find out. Without previous experience in dealing with highinnovation projects, students are at even more of a disadvantage because they can suffer crises of confidence that they can, in fact, succeed at the task. Experts will have experienced high innovation tasks previously and know that they can be undertaken successfully, by contrast.

\subsection{Recent Literature}

There is a considerable literature on the difference between experts and novices in engineering design. Dym et al. [3] provides a considerable review of the issues in engineering design thinking, teaching and learning. They delve into why engineering design is hard to learn and harder to teach. They then explore project-based learning, concentrating on firstyear and final-year courses.

They raise an issue that is core to the problem of teaching design, that of the need for both convergent and divergent thinking. Convergent thinking leads to factual answers with truth value. Divergent thinking leads to new concepts which lack truth value; they just are. Both are necessary. Convergent thinking establishes facts and supports deep reasoning while divergent thinking builds the concepts for which convergent thinking provides essential facts. Students are good convergent thinkers, and traditional engineering programs support convergent thinking models well. The divergent components are neither taught nor learned well, and are even more poorly assessed as they lack truth value. There is no "right answer"; indeed there are many answers, more or less applicable given other decisions made, and so their assessment is a judgement call. We suggest that the limited practical experience of a significant fraction of the professoriat results in their reluctance to make these judgement calls and so they focus instead on instruction that significantly favours convergent thinking.

A related issue is the degree of abstraction employed by experts in their knowledge nets as compared to novices. Research shows [1],[3],[4],[5],[6] that the novices' mental models of engineering problems are extremely concrete and complete but lack the abstraction that allows them to be generalized, are not focussed on the important issues, and are not classified for rapid retrieval. The mental representation of experts differ in all three respects. Note that it is the degree of abstraction that allows transferring knowledge to other domains, and so allow porting and building concepts appropriate to the new domains from concepts in already familiar domains. Thus, abstraction enables divergent thinking.

Hinds et al. [4] show that this difference between novices and experts in their ability to abstract is detrimental to the teaching of "static" skills, ones that do not have to be transferred to other domains. However, student performance on "dynamic" skills that are transferred to other domains is higher when they are taught by experts than by others. They show that static skills are best taught by those only a level or so above the students on Dreyfus' model of skills acquisition [2]. This suggests that the novice's rote performance may be better but that greater deep understanding is gained from 
experts.

In many ways, the problem with current teaching of engineering design is that we teach specific "packages" of material in some form of sequence with the result that the student often has a hard time learning the rich interconnectedness between the packets that seems to be the substrate on which expert engineering design is conducted. This is made abundantly clear through the work of Kinchin, Cabot and Hay [5] and Lande and Leifer [6] through their analysis of the concept maps of experts and novices. It is interesting to note that some effort has been made to assess students' progress through analysis of their concept maps as they move through the program. While the work is not complete, this approach shows promise.

The path to experthood appears from the research to require students to build a "knowledge net" from which to draw when developing a "chain of practice" for a particular problem [5]. The richness of the design space makes it necessary to abstract the knowledge in this net so as to make it more easily retrievable and to reduce its volume. It appears that this abstraction also allows the expert to apply the knowledge to wider variety of situations more easily. We posit that it also facilitates the creation of appropriate analogies and metaphors.

If true, then it is important that the student gain the insights necessary to abstract his/her knowledge in meaningful and effective ways. Starting with very little to no knowledge in the particular area, this is difficult because each additional example represents a huge (but slowly diminishing) part of the knowledge base gained to date. We suggest that far from helping to solve this problem, the teaching of small packages of material exacerbates it. While the professor well understands how the pieces fit together, it is evident that the student does not and so does not develop the connections between the packages that facilitate construction of the "knowledge net" and from there, development of "chains of practice" suitable for the problem at hand.

This is evident to every professor teaching engineering. How often have we heard "But the exam questions weren't like the assignments!' If the student doesn't have the knowledge net, nor the ability to create an appropriate chain of practice, then (s)he must fall back on mere pattern matching without the insight to know where and when the pattern can and should be distorted to suit the problem.

Without appropriate knowledge nets and chains of practice, students are disadvantaged during any and all assessments. In essence, we are punishing them for their lack of experience. They don't appear to "get it." Are we smarter than they are? No, only more experienced.

\subsection{An Aside: A Vexing Question}

The foregoing leads to a rather vexing question. If teaching is in little packages, the result of a reductionist approach to engineering, and the research focuses on small areas of engineering design teaching, as we are doing here, then we must ask:

Can the cure to reductionist teaching be found through reductionist research?

There is a concern that current research, including ours, is attempting to radically improve a large system by slightly tweaking each of its components. It would appear that instead, we might want to consider a more holistic view by using the classroom as a research lab incorporating the appropriate instrumentation to permit measurement of student learning of engineering design material.

\section{The Key Point}

The key observation is that

\section{The project is "high innovation" if the designer knows little of its domain.}

And so, almost everything that students undertake is high innovation, to them. It is all new. 
That is a really stressful way to live! Further, teaching the material as we typically do does not help. While the resulting knowledge is more transferable by the student, it is acquired with difficulty.

The modern design engineer must be able to form abstractions and to deal with uncertainty. We are seeking ways to educate our students so as to make them capable of creating, exploiting, transferring and classifying abstractions based on limited exemplar provided in an interactive learning environment that promotes rapid proof-of-concept prototyping.

\section{Our Approach}

Expert designers have two advantages in highinnovation projects. Although the problem may be largely new to them, they have built up, from experience, extensive relevant knowledge nets at various levels of abstraction, and they have confidence that they can develop a design process suitable for the task. They identify possible solutions based on their knowledge nets and then create proof-of-concept prototypes to test these solutions. This has the additional benefit of further enhancing their knowledge nets.

Students, however, do not have either advantage. They have little confidence in their ability to execute a design process, and they have extremely impoverished knowledge nets as evidenced by their concept maps [5],[6]. As a result, they cannot perform the exploration required and so they fall back on simple pattern matching.

We believe that learning to form useful abstractions can be taught, or at the least, can be experienced personally in the classroom and in labs. We posit that the right mix of projectbased learning [3] together with many opportunities to rapidly conceive, construct, test and assess proof-of-concept prototypes throughout all years of an engineering program will rapidly advance the student's ability to cre- ate and exploit abstractions while simultaneously building their knowledge nets and allowing them to gain confidence.

Current practice in many schools is to have a cornerstone project in first year and a capstone project in the last year. We believe that this is grossly unfair to students and is, in fact bad pedagogy. Why? In the first year, the cornerstone course is largely a means of showing students some aspects of engineering to improve retention and to motivate learning. In fact, they know very little engineering and so their designs and implementations are more craft than engineering. That is fine, but it does little to build the knowledge nets essential for engineering design.

The next major design challenge that they undertake is the final year capstone project. This is usually two terms duration, culminating in a report and presentation. While there may be a number of milestones associated with the project, students' experience is one of working ferociously hard on a project to meet timelines while taking other courses, and then they get a mark and the term is over. They do not have time to reflect on their process, nor to try some parts again so as to improve. Good teaching allows students to try, to fail, to discover why, and to try again so as to get it right. Capstone projects don't usually allow this.

Our approach is one of implementing a "Design Continuum" so that students have design opportunities appropriate to the course material, to their intellectual development and to their progress as design engineers. We have applied for renewal of the NSERC Chair in Design Engineering at Dalhousie, entitled the "Chair for Project-Integrated Design Engineering". The thrust of the proposal is to incorporate design and design projects at various levels throughout every program. At the end of the Chair tenure, we expect to be implementing "Program Projects", major projects around which significant parts of entire programs are 
wrapped and which span several years. This will have the following advantages:

- students will clearly understand that the boundaries between courses are largely artificial, a mere convenience for "package-based teaching",

- students will have significant and repeated opportunities to conduct proof-of-concept testing,

- it is anticipated that retention and recruitment will both increase substantially,

- students will become more self-directed as labs become more open-ended, in the sense that students will need to understand the problems that need to be solved for the next phase of the program project,

- students in the earlier years will be interacting and being guided by those in later years to the benefit of both,

- professors will find the students much more focussed on learning.

Some of these benefits have been experienced already in the author's two Design Methods courses, one in second year and one in third year.

We have a reduced version of the Design Continuum in the Electrical \& Computer Engineering department at Dalhousie. This requires students to undertake:

- the cornerstone course in first year

- a major design course in second year that has five design mini-projects,

- a major design course in third year that has one project that is the same for all groups, and

- a two-term capstone course in fourth year in which students undertake projects for local companies, and so all projects are different.

This has proved to be very effective and wellreceived by the students. Some of the other professors in the department are incorporating components of it in their courses, including a project to design and build a DC machine and a project develop an operating system and a control strategy to control, over the Internet, a multi-train model railroad This early Design Continuum was a "pilot" for the new Chair proposal. Some of the concepts from the Design Continuum have been incorporated in parts of our new curriculum for first and second year faculty-wide, and many have been incorporated in the Chair proposal.

\subsection{Teaching and Learning Environment}

Of particular interest is the teaching and learning environment. A normal engineering course at Dalhousie requires about 12 hours per week of a student's time, as follows: 3 hours in class, 3 hours for an assignment, 3 hours in lab and 3 hours writing up the lab. From this we see that fully half the students' time is devoted to the lab. Why, then, do labs often get short shrift?

We suggest that we need to radically change the teaching environment. We are considering implementing a combined classroom and lab as a pilot project. In this room, students sit at tables or benches, with computers and test equipment readily available and sunk into the table top so as to preserve sight lines. The professor teaches a concept, and then asks the students to implement that concept in some design exercise in hardware or by simulation. Results can be presented to the class immediately where they are discussed and explored.

The benefit of this environment is that students get to hear the material, then use it immediately for a real project or mini-project. Errors in understanding are caught and corrected early. Students become more involved with the work and the learning.

Have I ever seen a student fall asleep in lab? Never. But in class? Sadly, far too often. Why is that? In part, because they are not engaged. We believe that this new classroom will help us to achieve new levels of engagement. 
This environment allows the professor to wrap the course content around the labs and to teach both simultaneously. The students get an immersive environment in which they can try out their ideas rapidly. Professors get engaged, interested students that are learning at an exceptional rate.

\section{Author's Experience}

Gregson is a professor of Electrical and Computer Engineering and a past NSERC Chair in Design Engineering. He has over 30 years' experience in new product design in biomedical engineering, imaging, data acquisition and control, and in embedded systems. He founded or co-founded four startups that have developed four products that are being commercialized globally. He founded the iDLab at Dalhousie University with the mandate to assist companies with advanced design challenges. The iDLab undertook 26 projects for 18 companies over a period of seven years, with a total value of $\$ 1.7$ million. Of these, six have been, or are being commercialized globally.

The experience gained in these activities has been invaluable in the classroom and have informed his teaching to a considerable degree. Many of the issues seen in the classroom are echoed in industry where only infrequently are domain experts employed by the company. Instead, many smaller companies require their personnel to function across multiple domains. In many cases this means that those personnel may not progress beyond "competent" in the Dreyfus model of skills acquisition in any or at least most of the domains. This limits the quality or their design solutions and impacts the level of innovation.

\section{References}

[1] B.D. Crowell, The Creativity Matrix: An Extension To Axiomatic Design, M.A.Sc. Thesis, Dalhousie University, 2007.

[2] S.E. Dreyfus, S.L Dreyfus, "A five-stage model of the mental activities involved in directed skill acquisition", Operations Research Center, University of California, Berkeley, 1980.

[3] C.L. Dym, A.M. Agogino, O. Eris, D.D. Frey, L.J. Leifer, "Engineering design thinking, teaching and learning", Journal of Engineering Education, Jan 2005, pp. 103-120.

[4] P.J. Hinds, M. Patterson, J. Pfeffer, "Bothered by abstraction: The effect of expertise on knowledge transfer and subsequent novice performance", Journal of Applied Psychology, vol. 86, no. 6, 2001, pp. 1232-1243.

[5] I.M. Kinchin, L.B. Cabot, D.B. Hay, "Visualizing expertise: towards an authentic pedagogy for higher education", Teaching in Higher Education, vol. 13, no. 3, June 2008, pp. 315-326.

[6] M. Lande, L. Leifer, "Work in progress - Student representations and concepts of design engineering", 39th ASEE/IEEE Frontiers in Education Conference, San Antonio, TX, Oct 18-21, 2009, pp. T2F-1 - T2F-2 